\begin{tabular}{|l|l|l|}
\hline Received: November 2020 & Accepted: Februari 2021 & Published: April 2021 \\
\hline
\end{tabular}

\title{
Rancang Bangun Battery Monitoring System (BMS) berbasis LabVIEW
}

\author{
Ihsan $^{1}$, Angga Wahyu Aditya ${ }^{2 *}$ \\ ${ }^{1,2}$ Jurusan Teknik Elektro, Politeknik Negeri Balikpapan \\ *angga.wahyu@poltekba.ac.id
}

\begin{abstract}
The acceleration of the development of electric vehicles in Indonesia has been stated in the presidential regulation (Perpres) number 55 of 2019. The acceleration of the development of electric vehicles is motivated by the decreasing reserves of fuel oil and the danger of environmental pollution. Besides, the development of the Low-Cost Green Car (LCGC) vehicle concept has become the focus of research in several countries to combat environmental pollution. The development of technology for the components of the battery, the battery monitoring system (BMS), supports about $60 \%$ of the success of the development of electric vehicles. BMS is designed to accommodate the needs of the monitoring battery voltage, current, and temperature. The voltage sensor on the BMS is designed using the principle of a voltage divider by considering the working voltage of the analog to digital converter (ADC) microcontroller. The use of the ACS758 current sensor considers the maximum current requirements of the electric motor used. While the temperature sensor uses PT100. Serial communication is used to transmit data from the microcontroller to LabVIEW with the data transmission protocol in the form of two-digit voltage, current, and temperature readings. The data transfer protocol from the microcontroller is enumerated in the LabVIEW block diagram program and displayed on the front panel in graphical form.
\end{abstract}

Keywords : electric vehicle, BMS, LabVIEW, microcontroller

\begin{abstract}
Abstrak
Percepatan pengembangan kendaraan listrik di Indonesia telah tertuang di dalam peraturan presiden (Perpres) nomor 55 tahun 2019. Percepatan pengembangan kendaraan listrik ini dilatarbelakangi oleh cadangan bahan bakar minyak yang terus menurun dan bahaya pencemaran lingkungan. Selain itu, pengembangan konsep kendaraan Low-Cost Green Car (LCGC) menjadi fokus penelitian di beberapa negara untuk memerangi pencemaran lingkungan. Pengembangan teknologi komponen penyusun battery, battery monitoring system (BMS) menopang sekitar $60 \%$ keberhasilan pengembangan kendaraan listrik. BMS dirancang untuk mengakomodasi kebutuhan mengenai monitoring tegangan, arus dan temperatur battery. Sensor tegangan pada BMS didesain menggunakan prinsip pembagi tegangan dengan mempertimbangkan tegangan kerja analog to digital converter (ADC) microcontroller. Penggunaan sensor arus ACS758 mempertimbangkan kebutuhan arus maksimal dari motor listrik yang digunakan. Sedangkan sensor temperatur menggunakan PT100. Komunikasi serial digunakan untuk mengirimkan data dari microcontroller ke LabVIEW dengan protokol pengiriman data berupa data pembacaan tegangan, arus dan temperatur sebesar dua digit. Protokol pengiriman data dari microcontroller dicacah pada program block diagram LabVIEW dan ditampilkan pada front panel dalam bentuk grafik.
\end{abstract}

Kata kunci : kendaraan listrik, BMS, LabVIEW, microcontroller 


\section{Pendahuluan}

Filosofi pengembangan mobil listrik dipicu oleh: kelangkaan Bahan Bakar Minyak (BBM), peningkatan kesadaran lingkungan, perubahan gaya hidup, tingkat kemajuan teknologi dan perubahan kebutuhan pengguna. Pada tahun 2013, Chetan Mainin menginisiasi konsep 5C (Clean, Convenient, Connected, Clever and Cost Effective) yang menjadi faktor pengembangan kendaraan listrik sebagai salah satu solusi pengganti BBM dalam sektor transportasi [1].

Percepatan pengembangan kendaraan listrik nasional berbasis baterai untuk transportasi jalan telah tertuang dalam peraturan presiden (Perpres) No. 55 tahun 2019. Berdasarkan Rencana Umum Energi Nasional (RUEN), pada tahun 2025 pemerintah telah menargetkan pengembangan mobil listrik berbasis baterai sebanyak 2.200 unit. Pada tahun 2025, pangsa pasar mobil listrik diasumsikan sebesar $1 \%$ atau sekitar 20 ribu unit dari total penjualan kendaraan baru dan akan terus mengalami peningkatan secara bertahap mencapai $50 \%$ atau sekitar 36.5 juta unit pada tahun 2050 [2].

Pengembangan teknologi di bidang sistem elektronika dan penerapannya pada mobil listrik merupakan salah satu menjadi fokus riset tersendiri dalam mengembangakan teknologi transportasi untuk mendukung program pemerintah dalam percepatan kendaraan listrik [3], [4], [5], [6]. Pengembangan teknologi pada bidang baterai menopang sekitar $60 \%$ keberhasilan penelitian mengenai mobil listrik [2]. Pengembangan teknologi baterai mobil listrik saat ini berfokus pada penggunaan baterai lithium dengan fokus penelitian mengenai komponen penyusun baterai dan BMS [7], [8], [9], [10], [11].

Pengembangan BMS pada mobil listrik dikembangkan untuk memonitoring kondisi battery. Pada tahun 1998, BMS menggunakan battery jenis lead-acid battery (accu) [12]. Pada tahun 2012, standar pengembangan BMS untuk jenis battery li-ion atau lithium untuk memastikan ketersediaan energi, masa pakai dan keamanan sistem penyimpanan energy dengan parameter berupa tegangan, arus dan temperatur battery [9].

Publikasi ilmiah ini membahas mengenai monitoring kondisi battery pada mobil listrik berbasis laboratory virtual instrumentation engineering workbench (LabVIEW). Jenis battery yang digunakan adalah lead-acid battery 12 Volt / 40 Ah. Parameter monitoring yang digunakan pada BMS ini adalah tegangan, arus, dan suhu battery. Sistem BMS menggunakan motor listrik jenis brushless DC (BLDC) 1 kilo watt dengan tegangan nominal 48 Volt.

\section{Metoda Penelitian \\ 2.1. BMS}

BMS dirancang untuk memenuhi standar keselamatan dan mencegah kerusakan akibat masa pakai pada battery. BMS dibangun dan dirancang untuk memantau dan mengontrol penggunaan battery pada setiap sel-nya [13].

Battery pada umumnya terdiri atas rangkaian controller, sensor dan transmitter untuk menampilkan data pembacaan sensor. Parameter yang diukur pada BMS dapat berupa data tegangan, arus dan suhu battery secara real time. Pengembangan BMS dapat dilakukan pada sisi State of Charge (SoC) dan State of Health (SoH). SoC umumnya memberikan gambaran prosentase kapasitas yang tersisa dari suatu battery yang dihitung menggunakan metode perhitungan coulomb. Sedangkan SoH pada battery memberikan gambaran kondisi lain. Untuk mengidentifikasi SoH dapat menggunakan metode pengukuran langsung, metode berbasis model degradasi dan metode statistik, metode pengujian estimasi adaptif [14]. Metode pengukuran langsung melibatkan pengukuran arus, tegangan dan temperatur battery dimana untuk estimasi SoH hambatan dalam dan kapasitas baterai mengikuti standar [15]. Pengukuran hambatan menggunakan hambatan dalam battery yang dinyatakan dalam fungsi temperature [16]. Metode pengujian $\mathrm{SoH}$ menggunakan metode berbasis model degradasi dilakukan dengan menganalisis liion dan jumlah bahan aktif didalam battery. 
Metode ini sangat akurat namun rumit karena membutuhkan pemahaman mendalam mengenai mekanisme elektrokimia [17]. Pengukuran SoH dapat menggunakan metode probabilistik dan statistik yang memudahkan pengukuran tanpa perlu memahami mekanisme elektrokimia [18] [19].

\subsection{LabVIEW}

LabVIEW merupakan bahasa pemrograman berbasis grafis atau blok [20]. Program pada LabVIEW dikenal sebagai virtual instruments (VI) dikarenakan tampilan dan penggunaannya menyerupai instrumen sebenarnya. Software pada LabVIEW terdiri atas front panel, block diagram, function palette dan control palette. LabVIEW telah banyak digunakan diberbagai bidang penelitian seperti : proses management di industri [21], monitoring sinyal electrocardiogram (ECG) untuk pasien kardiovaskular [22], pengaturan motor induksi berbasis kendali cerdas [23], kendali proses yang dikomunikasikan dengan PLC [24] dan lain sebagainya. LabVIEW memungkinkan pemantauan dan pengaturan suatu sistem secara langsung (real-time) menggunakan graphical user interface (GUI), human machine interface (HMI) maupun supervisory control and data acquisition (SCADA) [25], [26], [27], [28].

\section{Hasil Penelitian}

\subsection{Konfigurasi Hardware}

BMS menggunakan 4 (empat) buah lead-acid battery yang memiliki tegangan tegangan nominal 48 Volt dengan kapasitas 40 Ah. Perancangan sensor tegangan yang digunakan menggunakan prinsip pembagi tegangan dimana tegangan nominal dari battery (48 Volt) dikonversi menjadi tegangan yang mampu terbaca oleh analog to digital converter (ADC) microcontroller (0 - 5 Volt). Sensor arus yang digunakan pada BMS ini adalah ACS 758 dengan kapasitas arus maksimal yang mampu diukur adalah $100 \mathrm{~A}$. Pemilihan sensor ACS758 didasarkan pada perhitungan kebutuhan dari arus maksimal yang digunakan oleh motor BLDC. Pengukuran temperatur menggunakan resistance temperature detector (RTD) PT100 yang ditempelkan pada battery. Gambar 1 menunjukkan arsitektur dari desain hardware pada BMS. Pembacaan sensor dan proses akuisisi data dilakukan oleh microcontroller. Data sensor pada microcontroller dikirmkan menggunakan komunikasi serial ke LabVIEW. Gambar 2 menunjukkan implementasi dari BMS.

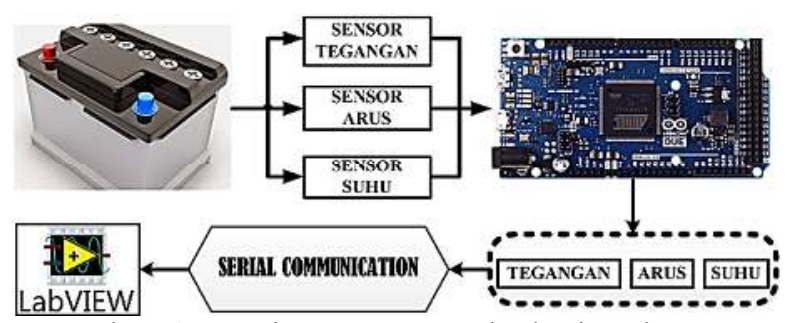

Gambar 1. Desain system BMS berbasis LabVIEW

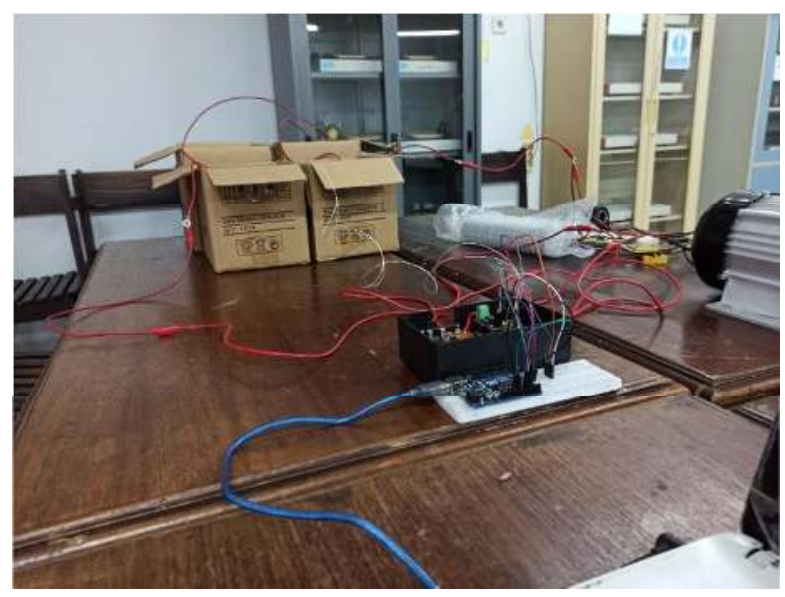

Gambar 2. Konfigurasi hardware BMS berbasis LabVIEW

\subsection{Program LabVIEW}

Program LabVIEW pada BMS berfungsi untuk menerima dan menampilkan data pembacaan sensor tegangan, arus dan suhu dari microcontroller. Komunikasi serial digunakan untuk mengirimkan data pembacaan sensor dari microcontroller ke LabVIEW. Protocol data yang digunakan untuk mengirimkan data sensor ditunjukkan oleh gambar 3. XX1 menyatakan data pembacaan sensor tegangan sebanyak dua digit, pembacaan data arus sebesar dua digit dinyatakan oleh XX2 sedangkan XX3 
menyatakan data pembacaan temperatur. Program block diagram LabVIEW untuk BMS ditunjukkan oleh gambar 4 dengan program front panel ditunjukkan oleh gambar 5 .

\section{\# XX1 , XX2 , XX3 *}

Gambar 3. Protokol pengiriman data sensor
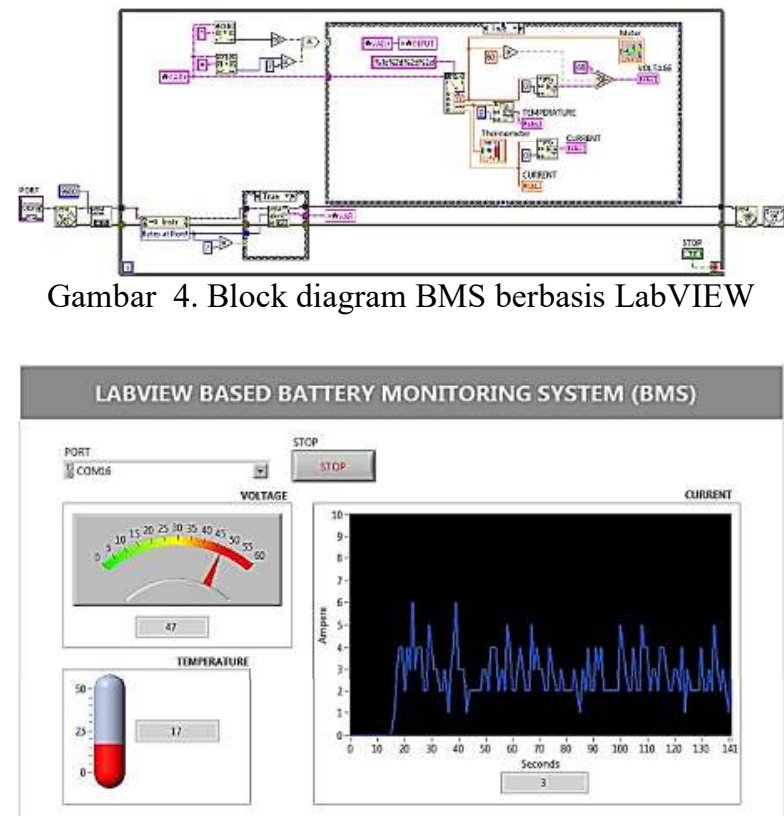

Gambar 5. Front panel BMS berbasis LabVIEW

\section{Kesimpulan}

BMS berbasis LabVIEW didesain untuk memonitoring kondisi battery menggunakan parameter tegangan, arus dan temperatur. Pembacaan sensor dan akuisisi data pada BMS dilakukan oleh microcontroller. Sensor tegangan pada BMS menggunakan prinsip pembagi tegangan, sensor arus yang digunakan adalah ACS 758 dan sensor suhu yang digunakan adalah RTD PT100. Data pembacaan sensor oleh microcontroller di kirimkan ke LabVIEW menggunakan komunikasi serial. Protokol pengiriman data yang digunakan untuk pengiriman data ditunjukkan oleh gambar 3 .

\section{Saran}

Diperlukan penelitian lanjutan untuk pengembangan monitoring $\mathrm{SoC}$ dan $\mathrm{SoH}$. Sistem monitoring kondisi battery dapat dikembangakan menjadi sistem manajemen battery / Battery Management System (BMS). Pengembangan lebih lanjut dapat dilakukan prediksi kondisi dan life time battery untuk memudahkan penggantian battery yang mengalami kerusakan.

\section{Daftar Pustaka}

[1] C. Maini, K. Gopal and R. Prakash, "Making of an 'all reason' electric Vehicle," in International Battery, Hybrid and Fuel Cell Electric Vehicle Symposium, Barcelona, 2013.

[2] BPPT, Indonesia Energy Outlook Dampak Peningkatan Pemanfaatan Energi Baru Terbarukan Terhadap Perekonomian Nasional, Jakarta: Pusat Pengkajian Industri dan Proses Energi (PPIPE) - Badan Pengkajian dan Penerapan Teknolog (BPPT), 2019.

[3] S. M. Fard, A. Khajepour, A. Goodarzi and E. Esmailzadeh, "Design and control of a narrow electric vehicle," in International Electric Vehicle Conference, Greenville, 2012.

[4] M. YAICH, M. R. HACHICHA and M. GHARIANI, "Modeling and Simulation of Electric and Hybrid Vehicles for Recreational Vehicle," in International conference on Sciences and Techniques of Automatic control \& computer engineering - STA, Monastir, 2015.

[5] A. Saleki, S. Rezazadeh and M. Changizian, "Analysis and Simulation of Hybrid Electric Vehicles for Sedan Vehicle," in Iranian Conference on Electrical Engineering, Tehran, 2017.

[6] A. Sriwilai, W. Pattaraprakorn, V. Chuti Prapat, C. Sansilah and P. Bhasaputra, "The Study on the Effect of Electric Car to Energy Consumption in Thailand," in 13th International Conference on Electrical Engineering/Electronics, Computer, Telecommunications and Information Technology (ECTI-CON), Chiang Mai, 2016.

[7] W. Chen, J. Liang, Z. Yang and G. Li, "A 
Review of Lithium-Ion Battery for Electric Vehicle Applications and Beyond," in International Conference on Applied Energy (ICAE2018), Hong Kong, 2018.

[8] C. Iclodean, B. Varga, N. Burnete, D. Cimerdean and B. Jurchiș, "Comparison of Different Battery Types for Electric Vehicles," in IOP Conference Series: Materials Science and Engineering, Pitesti, 2017.

[9] M. Brandl, H. Gall, M. Wenger, V. Lorentz, M.Giegerich, F. Baronti, G. Fantechi, L. Fanucci, R. Roncella, R. Saletti, S. Saponara, A. Thaler, M. Cifrain and W. Proschazka, "Batteries and Battery Management Systems for Electric Vehicles," in 2012 Design, Automation \& Test in Europe Conference \& Exhibition (DATE), Dresden, 2012.

[10] X. Jun and L. Zhou, "Lithium battery remote monitoring system for vehicle mounted," in 2017 29th Chinese Control And Decision Conference (CCDC), Chongqing, 2017.

[11] W. Menghua and X. Bing, "A Real-Time Android-Based Monitoring System for the Power Lithium-Ion Battery Used on EVs," in 2017 10th International Conference on Intelligent Computation Technology and Automation (ICICTA), Changsa, 2017.

[12] P. Sinclair, R. Duke and S. Round, "An adaptive battery monitoring system for an electric vehicle," in 1998 International Conference on Power Electronic Drives and Energy Systems for Industrial Growth, Perth, 1998.

[13] S. A. Mathew, R. Prakash and P. C. John, "A smart wireless battery monitoring system for Electric Vehicles," in 12th International Conference on Intelligent Systems Design and Applications (ISDA), Kochi, 2012.

[14] F. A. Shah, S. S. Sheikh, U. I. Mir and S. O. Athar, "Battery Health Monitoring for Commercialized Electric Vehicle
Batteries: Lithium-Ion," in 5th International Conference on Power Generation Systems and Renewable Energy Technologies (PGSRET), Istanbul, Turkey, 2019.

[15] Y. Xing, E. W. M. Ma, K. L. Tsui and M. Pecht, "Battery management systems in electric and hybrid vehicles," Energies, vol. 4, no. 11, pp. 1840 - 1857, 2011.

[16] K. M. Tsang and W. L. Chan, "State of health detection for Lithium ion batteries in photovoltaic system," Energy Conversion and Management, vol. 65, pp. 7-12, 2013.

[17] M. Ouyang, X. Feng, X. Han, L. Lu, Z. $\mathrm{Li}$ and $\mathrm{X}$. He, "A dynamic capacity degradation model and its applications considering varying load for a large format Li-ion battery," Applied Energy, vol. 165, pp. 48-59, 2016.

[18] S. Thein and Y. S. Chang, "Decision making model for lifecycle assessment of lithium-ion battery for electric vehicle--A case study for smart electric bus project in Korea," Journal of Power Sources, vol. 249, pp. 142 - 147, 2014.

[19] Z. He, M. Gao, G. Ma, Y. Liu and S. Chen, "Online state-of-health estimation of lithium-ion batteries using Dynamic Bayesian Networks," Journal of Power Sources, vol. 267, pp. 576 - 583, 2014.

[20] S. Wardoyo, R. Munarto and V. P. Putra, "Rancang Bangun Data Logger Suhu Menggunakan Labview," JURNAL ILMIAH ELITE ELEKTRO, vol. 4, no. 1, pp. $23-30,2013$.

[21] S. Venkatlakshmi, S. Vivekanandhan, S.Revathi, E. Arul and C.Paramasivam, "Industrial Process Management using LabVIEW," IOSR Journal of Electronics and Communication Engineering (IOSRJECE), vol. 5, no. 6, pp. 46-56, 2013.

[22] O. P. Singh, D. Mekonnen and M. B. Malarvili, "Labview Based ECG Patient Monitoring System for Cardiovascular Patient Using SMTP Technology," Journal of Medical Engineering, pp. 1-9, 
2015.

[23] H. H. FAKHRUDDIN, H. TOAR, E. PURWANTO, H. OKTAVIANTO, R. A. N. APRIYANTO and A. W. ADITYA, "Kendali Kecepatan Motor Induksi 3 Fasa Berbasis Particle Swarm Optimization (PSO)," ELKOMIKA: Jurnal Teknik Energi Elektrik, Teknik Telekomunikasi, \& Teknik Elektronika, vol. 8, no. 3, pp. 477-491, 2020.

[24] A. S. Ashtekar, B. J.Parvat and C. B. Kadu, "Application of MODBUS to Communicate the PLC and Lab VIEW for Real Time Process Control," International Journal of Emerging Science and Engineering (IJESE), vol. 1, no. 11, pp. 41 - 45, 2013.

[25] S. B, D. S. K, Dr.D.Sharmila, B. R. B, M. S. K and VEDIK, "SCADA Application Development Using LabVIEW," International Journal of Engineering and Innovative Technology (IJEIT), vol. 3, no. 2, pp. 407 - 410, 2013.

[26] D. N. G, S. R. P, V. A, C. K and A. Tanzeel, "Low-Cost Data Acquisition System with LabVIEW GUI for RealTime Flight Data Transmission in UAVs," International Journal of Engineering Research \& Technology (IJERT), vol. 9, no. 3, pp. 574-579, 2020.

[27] H. S. Hasan, M. Hussein, S. M. Saad and M. A. M. Dzahir, "Graphical User Interface (GUI) for Local Positioning System Based on Labview,"
International Journal of Machine Learning and Computing, vol. 9, no. 2, pp. 236 - 241, 2019.

[28] F. Adamo, F. Attivissimo, G. Cavone and N. Giaquinto, "SCADA/HMI Systems in Advanced Educational Courses," IEEE Transactions on Instrumentation and Measurement, vol. 56, no. 1, pp. 4-10, 2007. 